\title{
Imagens-totens e circulação: a chancela jornalística no caso Michael Jackson
}

\section{Ana Paula da Rosa}

\section{Resumo}

Este artigo pretende investigar as estratégias que são promovidas para pôr em circulação as imagens jornalísticas. Trata-se, então, de um estudo sobre o que está distribuído midiaticamente e que é reinscrito em dispositivos diversos, portanto ao mesmo tempo circulação e circularidade. Assim, parte-se do pressuposto de que, cada vez mais há crescente número de imagens ofertadas, contudo, há um diminuto número de imagens que se fixam, as chamadas vetoras, ou que se tornam totens exatamente por seu potencial de fixação e autorreferencialidade, pois convocam estruturas profundas do imaginário e são chanceladas jornalisticamente.

\section{Palavras-Chave}

Fotojornalismo. Midiatização. Símbolos. Circulação.

Ana Paula da Rosa I anarosa208@yahoo.com.br Doutora em Ciências da Comunicação pela Universidade do Vale do Rio dos Sinos (Unisinos), mestre em Comunicação e Linguagens da Universidade Tuiuti do Paraná (UTP) e jornalista pela Universidade de Passo Fundo (UPF). Atualmente é professora e pesquisadora no Programa de Pós-graduação em Ciências da Comunicação da Unisinos.

\section{Entre a midiatização e o objeto em jogo}

Quando se pensa em Comunicação, hoje, os antigos parâmetros parecem não mais dar conta: o processo comunicativo mudou. A tecnologia da informação afetou diretamente os modos de transmissão da informação. 0s dispositivos estão acessíveis a todos de maneira que as lógicas midiáticas que antes eram inerentes apenas às instituições que tinham a comunicação como seu fazer, portanto, midiáticas, passaram a se volatizar e espalhar-se por todas as instituições e campos da vida num processo que Pedro Gilberto Gomes (2004) denominou de midiatização da vida. Este fenômeno mudou o modo de ser do homem no mundo. Muniz Sodré (2006, p. 99) aponta para um bios midiático que é uma "transformação técnica do espaço-tempo, adequada às novas estruturas e configurações da vida social".

Neste sentido, Ferreira (2008) afirma que a midiatização diz respeito à unificação e diferenciação dos mercados discursivos a partir de três dimensões que se afetam mutuamente: processos comunicacionais, contextos sociais 
e dispositivos midiáticos. Ressalta-se que os dispositivos não são entendidos apenas em sua dimensão técnica e tecnológica, mas, como um conjunto de materialidades e, ao mesmo tempo, um conjunto de intersecções com os demais processos.

Ferreira (2009) destaca ainda que a midiatização só pode ser compreendida a partir da circulação. No entanto, ao frisar isto o autor propõe um contraponto à noção de circulação ou de feedback do sistema clássico de comunicação, uma vez que na circulação não há uma separação evidente entre produção e recepção, ao contrário, na esfera da midiatização estes papéis são constantemente alternados e a produção é compartilhada ou ocorre a partir de reinscrições. Há uma produção-consumidora e ao mesmo tempo um consumo-produtivo.

Esse duplo processo produz diversas transformações nas disposições e dispositivos midiáticos, em suas relações com as instituições e indivíduos que os disputam, mobilizam e os desenvolvem. Os processos midiáticos somam, portanto diversas circulações - emissão/recepção, emissão/recepção/emissão e recepção/emissão/ recepção - transformadas pela midiatização das instituições (portais, novas configurações tipo Igreja Universal do Reino de Deus) e dos indivíduos (blogs, facebook, MSN). Todos, emissores e receptores, estão inclusos no processo de produção (FERREIRA, ROSA: 2011, p. 22).

Deste modo, o que se pretende com este artigo é investigar como se dá o processo de circulação/ circularidade das imagens intermidiáticas tendo como foco as imagens da morte de Michael Jackson. Parte-se do pressuposto de que muitas imagens jornalísticas são reapropriadas e reinscritas na própria midiatização, de modo que lógicas midiáticas são mobilizadas na transformação de uma imagem em totens dos acontecimentos, ou seja, ganham um poder de permanência nos meios. 0 que se busca responder é como se dá a totemização pela midiatização?

\subsection{Lógicas midiáticas mobilizadas na transformação de uma imagem em símbolo do acontecimento}

Ao tomar como ponto inicial das operações midiáticas o fato de que as instituições que não possuem fins jornalísticos como seu fazer se valem de estratégias também midiáticas para alcançar o campo das mídias, percebe-se que, cada vez mais, os fatos vêm sendo colocados em uma situação de secundários em relação aos sentidos gerados pelas coberturas jornalísticas. Benetti (2010), Charaudeau (1997) e, Rodrigues (1993) procuram distinguir fato e acontecimento, sendo o fato aquilo que está dado, da ordem do que ocorre, e o acontecimento é algo a ser criado. Quéré (2005) destaca que 0 acontecimento é mais que um fato, ele é criador de sentidos e, portanto, desperta experiências. Tais experiências são inscritas na circulação, sendo que esta surge onde há troca, isto é, reconhecimento de um valor, onde produção e recepção se dizem acordo. Portanto, compreender a circulação é compreender como se dá o trabalho de construção do sentido e como o sentido se transforma ao longo do tempo. Para Jairo Ferreira (2007), é na circulação que 
o processo de produção de sentido se efetiva. A circulação, a partir desta visada, é, portanto, um processo em que o sentido circula, muda, altera-se conforme a lógica dos meios que, ao sintetizarem fatos na forma de discursos (imagéticos ou não), reinterpretam, gerando outras formas de vínculos.

Isso pode ser percebido na geração das imagens do caso Michael Jackson, onde a forma como 0 acontecimento foi produzido é muito significativa até mesmo pela invisibilidade resultante da ausência de registros fotográficos do momento da morte. 0 cantor foi não apenas "mantido vivo", como também idolatrado através da inserção de imagens de arquivo. Apesar das tentativas de reconstituir o momento da morte, mesmo que verbalmente, a maneira de ilustrar o seu falecimento é que possibilitou a eternização da imagem do cantor como um astro.

Ante 0 exposto fica evidente que 0 contexto do fato altera sua transformação em acontecimento, porém, interessa pensar que há lógicas midiáticas que são mobilizadas para transformar uma imagem em símbolo. Contudo, símbolo de quê?

E para quê tal esforço? A imagem de Michael Jackson negro transformada em símbolo permite cultuar uma memória positiva do astro e barrar as negativas. As imagens vetoras são símbolos de fatos que perdem tangibilidade, mas que tem esta característica recuperada pela sua retomada constante via exposição em dispositivos. Entretanto, não é a repetição que torna a imagem simbólica, mas a sua capacidade de constituir-se no próprio acontecimento, deslocando a relação com o referente, capacidade esta só possível a partir das estratégias e lógicas que serão recuperadas e sistematizadas a seguir. Tomando como ponto de partida três dimensões semio-técnica, sócio-antropológica e comunicacional ${ }^{1}$, 0 caso foi estudado em três movimentos metodológicos: a) leitura descritiva das imagens; b) relações contextuais concretas em meios jornalísticos; c) apropriações de atores individuais. Destaca-se que os materiais analisados são aqueles postos em distribuição e vistos na perspectiva dos três círculos do esquema da midiatização (instituições midiáticas, não midiáticas e atores midiatizados). Somente efetuadas estas etapas aqui sintetizadas é que se produz inferências que levam em conta a discussão da totemização, ou seja, um terceiro que não possui mais uma ligação direta com um primeiro, ainda que ele esteja ali, mas que passa a substituir o referente, numa espécie de simbolização de si mesmo.

\section{Indícios da construção de imagens- sínteses do caso}

Michael Jackson morreu no dia 25 de junho de 2009, em condições não bem esclarecidas, mesmo

Semio-técnica diz respeito à multiplicidade de vozes presentes em uma imagem; já a sócio antropológica, baseia-se nos movimentos de produção e consumo que convocam estruturas do social e o comunicacional que dá conta dos valores compartilhados no que deve ser distribuído. 
após o julgamento do médico do cantor, ocorrido em 2011, e que resultou em sua condenação. 0 fato por si só merecia ser noticiado, primeiro, por se adequar a diversos critérios de noticiabilidade, dentre os quais a pertinência e a relevância social; segundo, por se tratar de uma celebridade forjada para e pela própria mídia. A expressão forjada se refere ao fato de que a carreira de Michael Jackson iniciou em um programa televisivo infantil, em 1964, e foi, gradativamente, sendo construída sob os holofotes até os escândalos com o suposto abuso sexual de crianças em 1993. No entanto, as operações de midiatização da morte do cantor propiciaram uma espécie de comoção mundial, uma vez que a mídia transformou sua morte em um circo midiático, primeiro, com a reconstituição do fato e, mais tarde, com a eternização de sua imagem para legitimá-lo como o maior astro do pop.

A morte de Michael Jackson foi anunciada, em primeira mão, pelo site www.TMZ.com, pertencente ao grupo Time Warner. As primeiras imagens que obtiveram acesso a processos de distribuição em dispositivos midiáticos mostram o cantor entubado pelos médicos ou sendo transportado em uma maca. A fotografia, feita com câmera de celular, foi produzida através do vidro da janela da ambulância, isso é evidenciado pelo reflexo luminoso na perna do paramédico no canto direito da imagem. Além disso, o flagrante aproximado permite um plano fechado do rosto do cantor, mostrando o momento em que 0 mesmo era reanimado. Tal fotografia é forte em dois aspectos: primeiro, por apresentar a crueza da situação do cantor e, segundo, por permitir que o espectador da imagem se sinta espiando através do vidro, ou seja, colocar 0 leitor como um contemplador da cena devido à proximidade do registro. Esse efeito amplia 0 potencial de circulação da imagem, o que pôde ser comprovado com sua inserção na maioria das publicações. Assim, o registro rápido transformou-se no acontecimento.

Não sendo o bastante, a polícia impediu 0 acesso de repórteres ao local do ocorrido, o rancho Neverland, ficando a morte do cantor atrelada à imagem flagrada. Em contrapartida à escassez de imagens da morte, a vida de Michael Jackson foi marcada por um excesso de imagens, isto é, arquivos com fotos de sua carreira foram disponibilizados pelas gravadoras do cantor, bem como por sua família. Até mesmo o novo videoclipe do astro, mantido sob sigilo, serviu para construir 0 palco de sua morte, como se fosse uma morte arquitetada também para a mídia. A inscrição da morte do artista em inúmeros dispositivos midiáticos se deu automaticamente após 0 anúncio do fato. Entretanto, chama a atenção que mediante a ausência de uma imagem que representasse a morte, foi preciso recuperar a imagem do cantor como ídolo.

Desta forma, uma série de imagens foi sendo reapresentada e reinscrita na circulação, caso dos álbuns Thriller, Bad e Black or White. Muitas fotografias de shows do artista foram reexibidas, 


\section{¿ecompós}

www.e-compos.org, br $^{-}$

| E-ISSN 1808-2599 |

Figura 1: Fãs acompanham o funeral em telões públicos

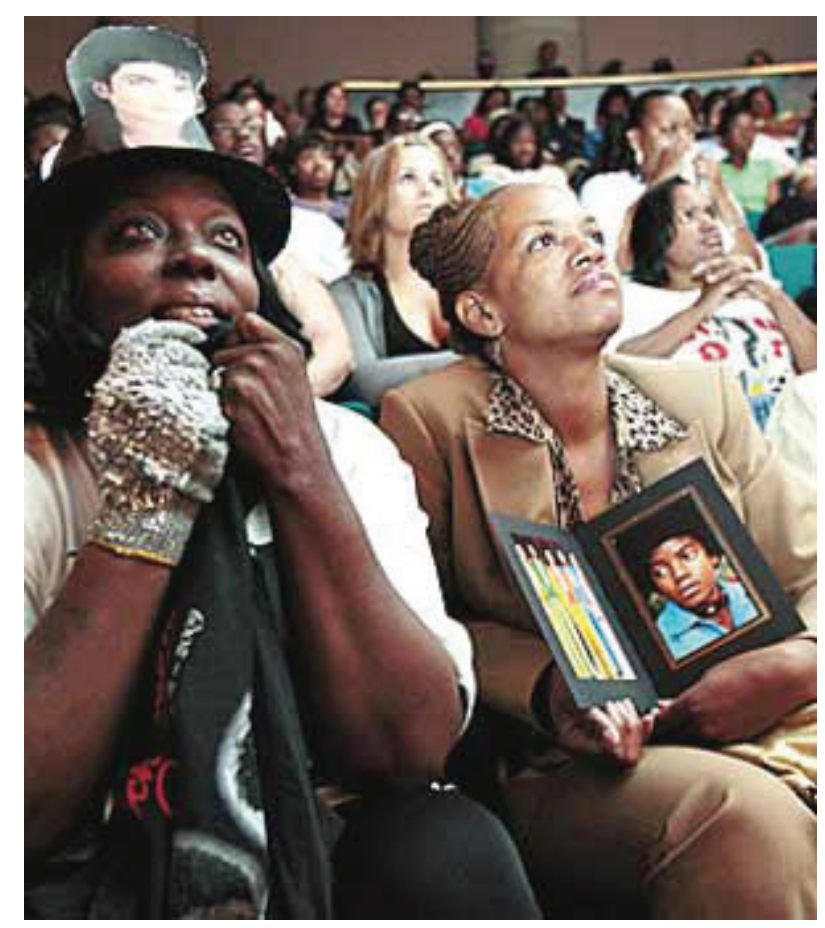

Fonte: Acervo pessoal da autora

Figura 2: Telão com montagem de imagens de Michael Jackson. Jornal Zero Hora

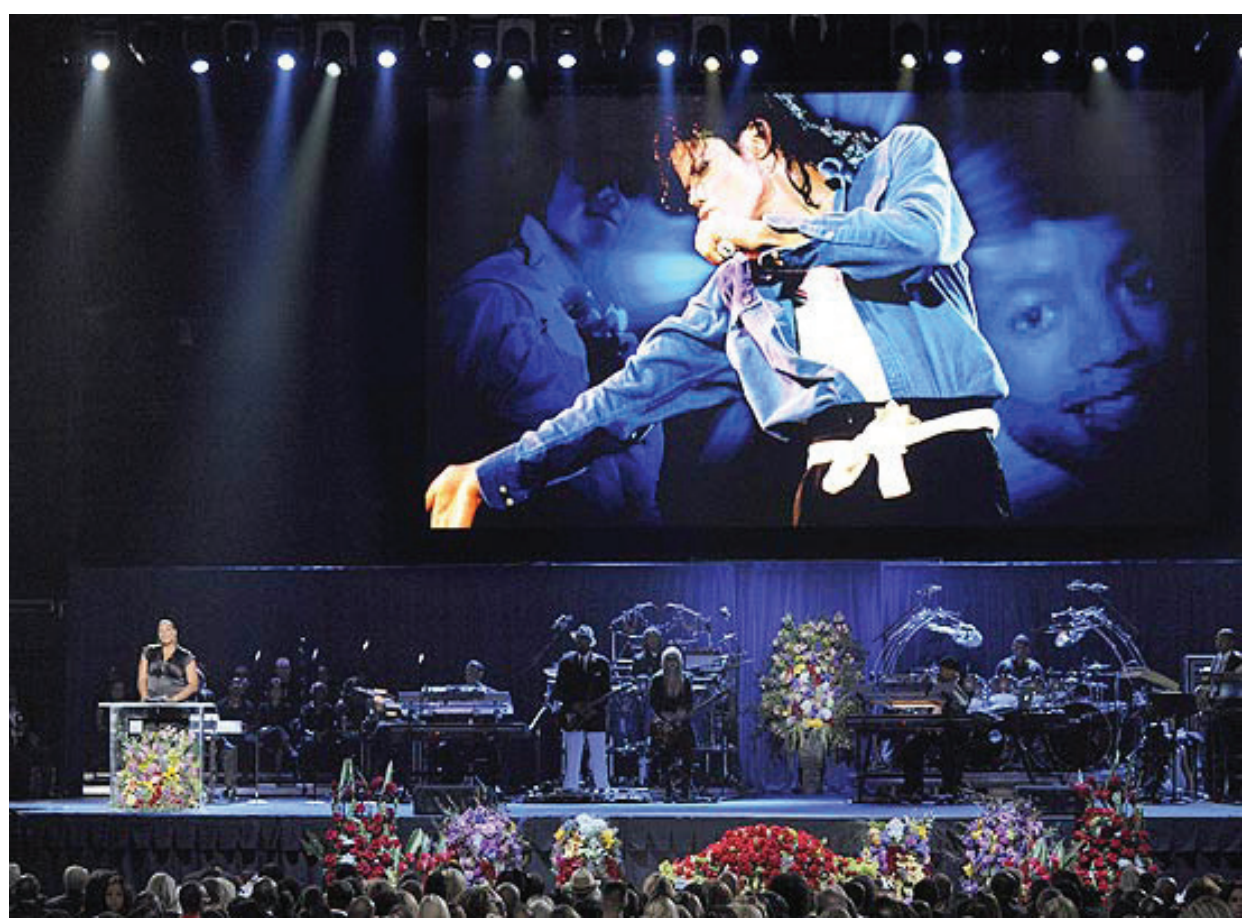


sendo que as da acusação do cantor de pedofilia ou de seu julgamento foram totalmente banidas no processo de circulação. Além disso, no caso Michael Jackson, os atores individuais tiveram um papel importante, uma vez que a legião de fãs contribuiu para rejeitar ou aceitar os discursos produzidos. Nestas imagens (Figura 1), observase que os fãs também contribuíram para a eleição da imagem-síntese e, portanto, simbólica, restringindo a inscrição de outras imagens.

Ou seja, no caso Michael Jackson é preferível manter e ampliar a distribuição das imagens de arquivo do que fazer isso com imagens atuais da repercussão de sua morte. Desta maneira, mais do que os fãs, as imagens do velório e do funeral do cantor ganharam grande visibilidade. De um lado, em função do fato em si ter sido transformado em um show e, de outro, pela exploração imagética do cantor, seja no discurso emocionado dos filhos, seja nas fotografias e vídeos veiculados.

\section{A fotografia acima, feita no estádio onde 0} funeral do cantor foi realizado, no dia 7 de julho de 2009, está dividida em três partes lineares. Na linha mais inferior verificam-se apenas as cabeças dos fãs e dos convidados, já na segunda linha, que agrega um pouco de profundidade de campo, observam-se os artistas e a banda que orquestraram o show. Já na terceira e última linha, a mais superior, tem-se uma montagem da imagem de Michael Jackson em um de seus shows na década de 1990 e de fundo há outras fotografias do cantor em momentos diversos de sua carreira.
Isto significa que a imagem acima, feita de modo a abranger todo o palco, evidencia a presença mágica do cantor que se agiganta diante da cena, promovendo ainda mais 0 apagamento de outras imagens existentes.

Desta forma, têm-se, como indícios da construção da imagem-síntese da morte de Michael Jackson, seis elementos: 1) a ausência de imagens que retratem a morte efetivamente; 2) a restrição ao local do fato pela polícia e pela família; 3) a retomada das imagens do cantor no início e auge da carreira em detrimento das imagens dos escândalos; 4) valorização da imagem de Michael Jackson negro pelos próprios atores individuais, aqui, como fãs; 5) uma vitimização do cantor através de fotomontagens e de relatos de amigos e colegas; 6) a exclusão de imagens que maculem a imagem do astro, sendo tal exclusão articulada na interação entre instituições midiáticas e atores individuais midiatizados. Desta forma, o que se evidencia, no caso Michael Jackson, é que após a sua morte, sua imagem foi reconstruída, retomada para os momentos anteriores aos escândalos que 0 cercaram a ponto de estes desaparecerem.

\subsection{Exclusões e inclusões: orquestrações midiático-jornalísticas}

Após 0 anúncio da morte, as instituições jornalísticas passaram a buscar informações diferenciadas para produzir edições especiais a respeito do ocorrido e, principalmente, 


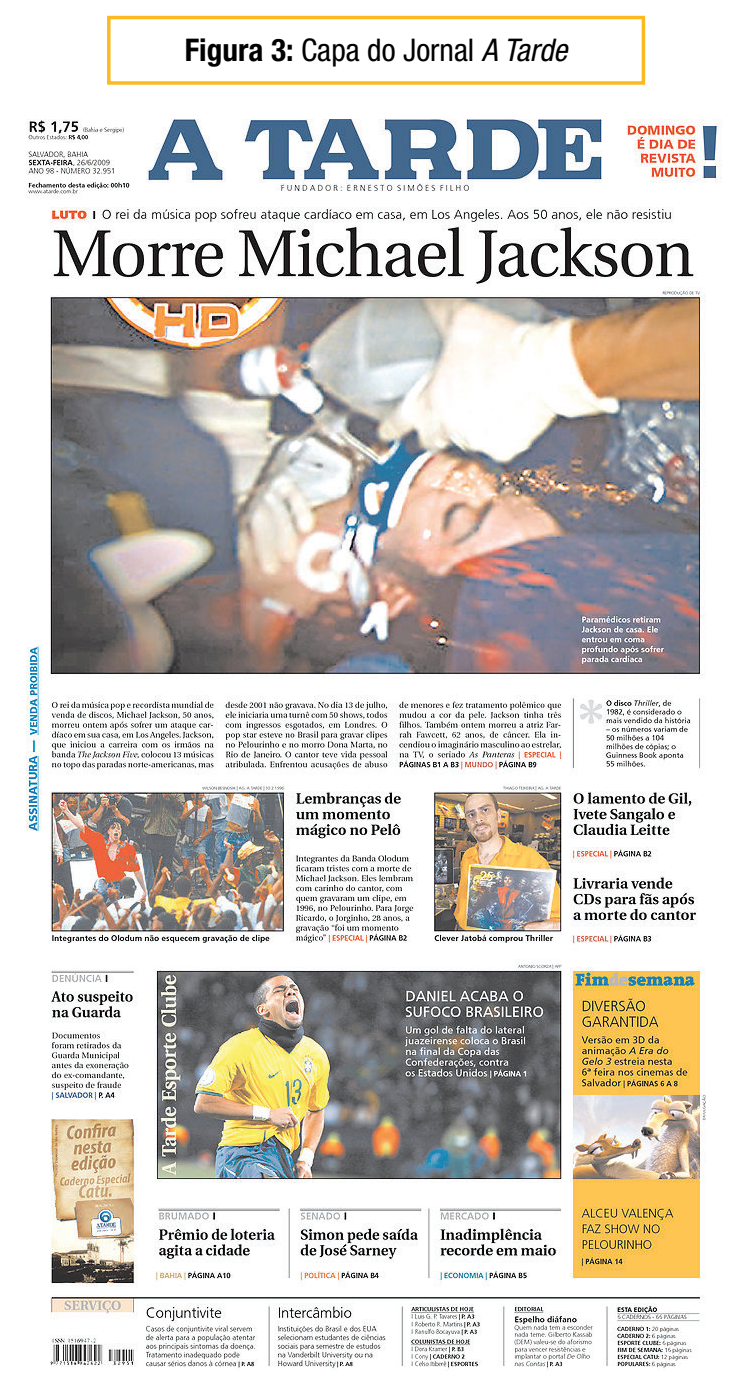

Fonte: Newseum, 2009.

alguma imagem que comprovasse tal fato.

Assim, a morte do astro foi apresentada a partir da reconstituição do fato via publicação da transcrição, ponto a ponto, do diálogo do empregado de Michael Jackson com 0 atendente da emergência. Deste modo, o uso "casado" da imagem com o texto, transcrito de uma gravação telefônica, permitiu atribuir a veracidade do acontecido e a "reocorrência" do fato, ou seja, não basta reconstruir a cena, é preciso revivê-la midiaticamente.
0 jornal $A$ Tarde (Figura 3), por exemplo, trouxe como imagem principal, de sua edição de 26 de junho de 2009, a fotografia de Michael Jackson sendo atendido por paramédicos, disposta em quatro colunas e, logo abaixo da manchete, "Morre Michael Jackson". A linha fina especifica os motivos da morte, ou seja, ataque cardíaco, e enfatiza o status de rei do pop, o que foi reproduzido em praticamente todas as publicações noticiosas. Destaca-se, neste caso específico do jornal $A$ Tarde, que a fotografia 
CLIPPERS SELECT BLAKE GRIFFIN WITH TOP PICK IN NBA DRAFT. c1

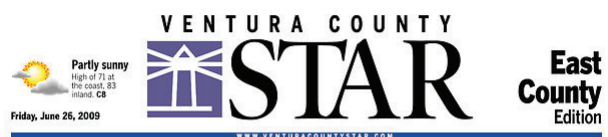

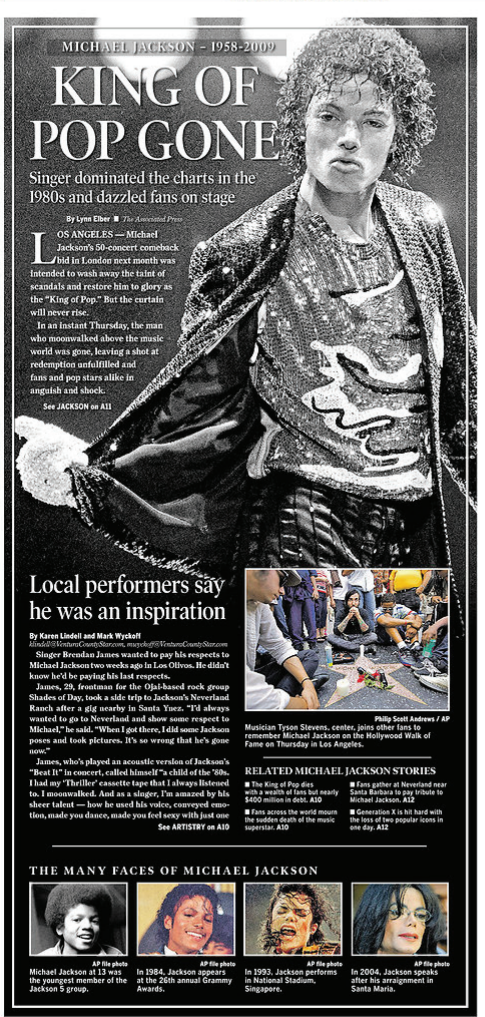

GIRL'S BODY BELIEVED FOUND

- FORMAL CHARGES EXPECTED TODAY AGAINST TWO IN DEATH OF 2\%-YEAR-OLD
COLUMNIST JERRY DAVICH SAYS MOST OF US EXPECTED TRAGIC OUTCOME, A3

CHESTERTON/VALPARAISO

most-Iribune

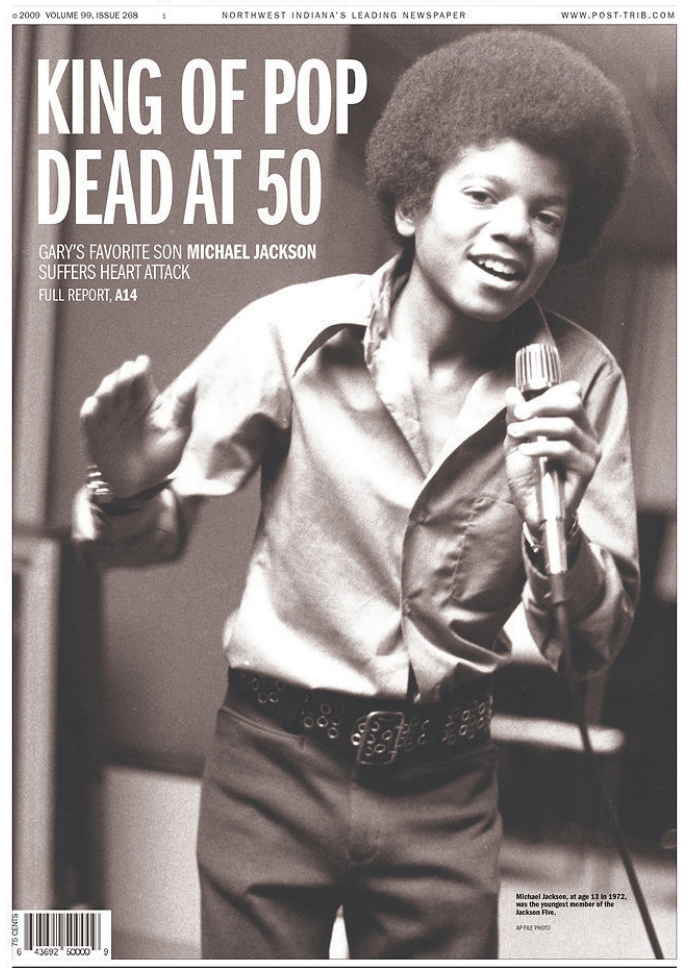

Fonte: Newseum, 2009.

carrega parte da logomarca da Entertainment

Tonight ET HD, um site focado em vídeos e

notícias de celebridades. A edição da fotografia

retirou o ET, mas o HD permaneceu na imagem.

Isto revela a escolha da instituição midiática

em apresentar a morte em si de Michael, ainda

que a única imagem existente fosse esta obtida

através de câmeras de celular e com baixa

qualidade, deixando entrever a presença de

outro dispositivo.
Desta forma, na ausência de fotografias que

pudessem, efetivamente, mostrar o momento

da morte, a cobertura jornalística focou-se em

resgatar imagens de arquivo do astro e em eleger

as imagens a serem publicadas. De um lado,

as agências de notícia que disponibilizaram

bancos de imagens do astro, e de outro, as

próprias instituições midiáticas jornalísticas, reconstruindo a trajetória do artista para recolocá-lo no trono do rei do pop. 


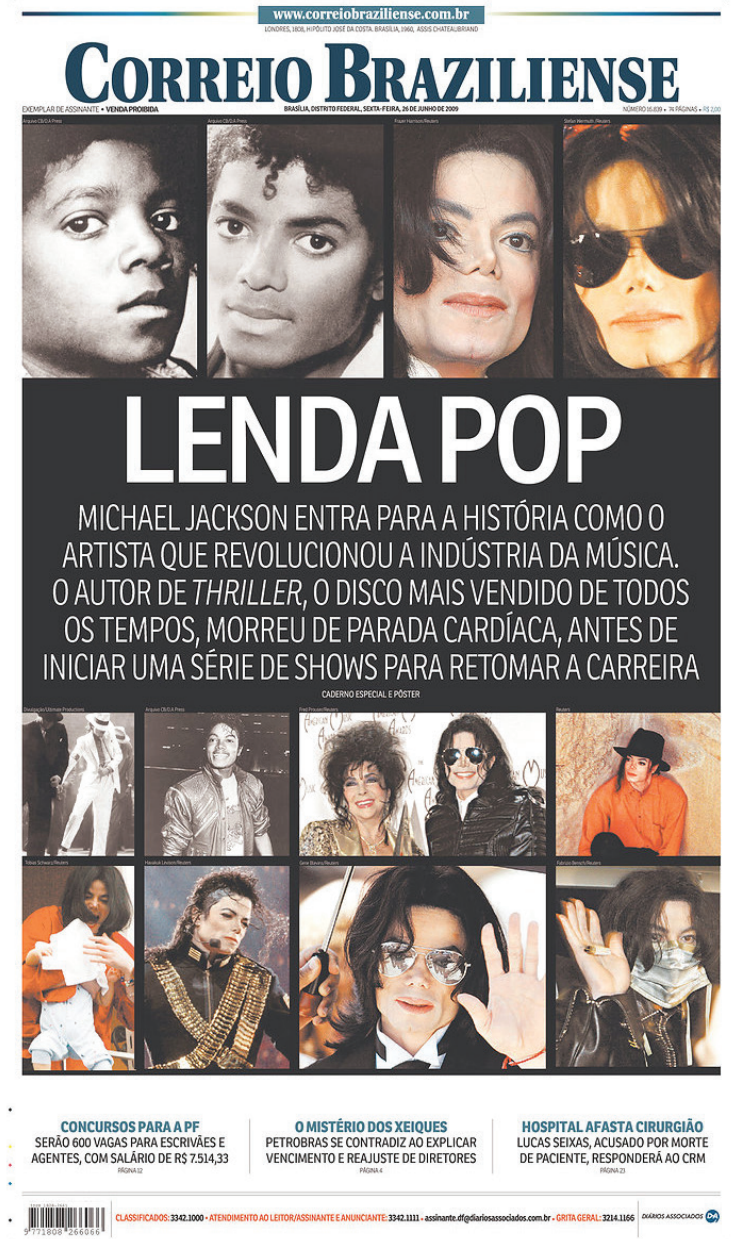

Fonte: Newseum, 2009.

Nas publicações acima, por exemplo, percebe-se que 0 Star e o Post Tribune optaram por imagens do início da carreira de Michael Jackson para ilustrar sua morte. As manchetes trazem a ideia da despedida ao rei do pop, o mesmo acontece nas capas de outros jornais. As manchetes "0 rei está morto" e "Adeus ao rei do pop" apenas enfatizam o processo de valorização imagética pelo qual Michael Jackson passou após sua morte. Isto é, morto, o cantor foi revitalizado como ídolo.
Com base no mencionado acima, as instituições midiáticas são autorizadas, socialmente, a quebrar a última imagem de Michael Jackson. 0 seu apagamento acontece pelo reavivamento das imagens do auge de sua carreira que já não colonizavam mais a memória visiva. Os sucessivos escândalos em que 0 cantor estava envolvido haviam retirado de circulação as imagens do astro como um cantor de sucesso ou como um dançarino criador do passo moonwalk. Com sua 
Figura 7 e 8: Thriller em capa de mau gosto do Meia Hora e 0 panamenho Crítica traz a trajetória do astro
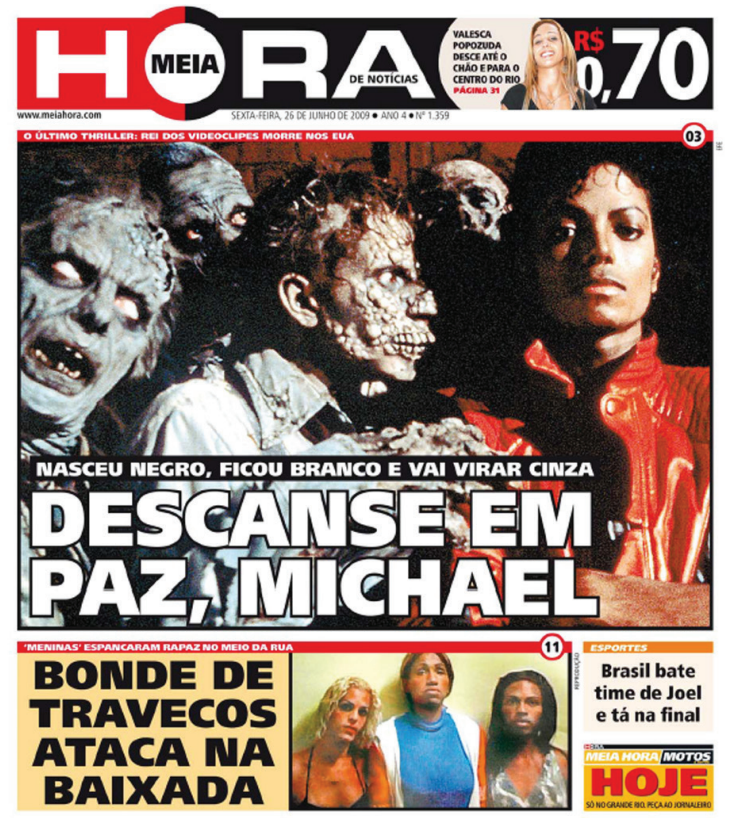

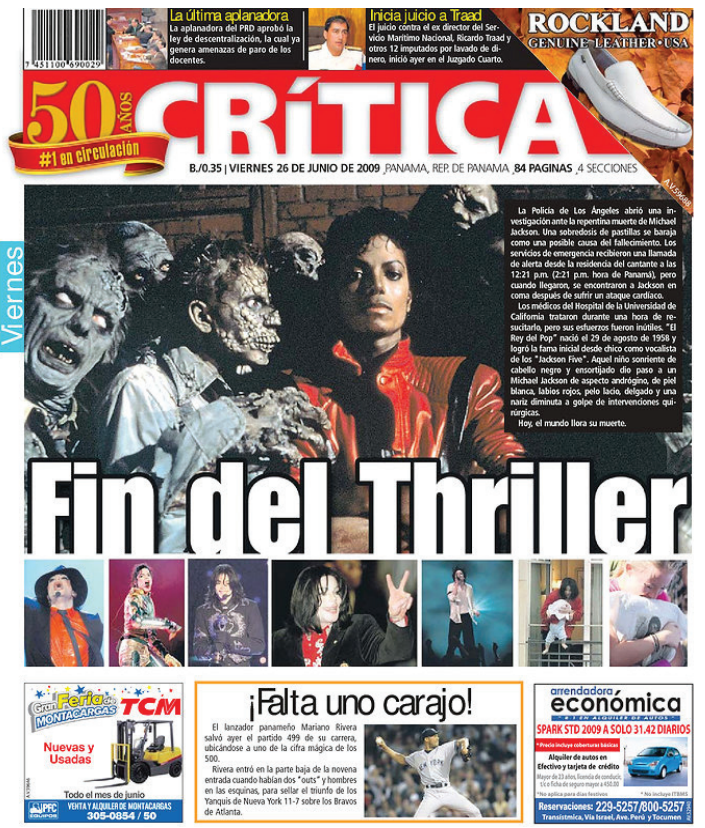

Fonte: Arquivo do jornal. e Newseum, 2009. morte, as imagens de suas dezenas de plásticas, a perda da cor e até mesmo o julgamento de pedofilia, imagens estas produzidas e reiteradas pela mídia, sofreram um processo de apagamento ou de exclusão da circulação, tendo em vista que outras imagens são eleitas para sintetizar 0 acontecimento. 0 único dispositivo midiático jornalístico que trouxe à tona fotografias dos momentos mais atuais do cantor foi o jornal brasileiro Correio Braziliense.

Nesta capa, percebe-se uma preocupação com a escolha das imagens para compor a edição, pois as quatro primeiras fotografias foram escolhidas por ângulos, isto é, a primeira e a terceira trazem o cantor com o rosto em diagonal, já a segunda e a quarta, mais de frente. Tais imagens também se diferenciam pelas cores, as duas primeiras em preto e branco e as duas últimas coloridas. Abaixo da manchete "Lenda Pop", outras oito fotografias foram dispostas, como um relato visual dos principais fatos que marcaram a carreira do astro, inclusive a polêmica imagem, banida de todas as demais publicações, da apresentação do filho de Michael Jackson na sacada de um hotel na Alemanha. As duas últimas imagens desta sequência mostram o cantor acenando após a absolvição no julgamento em 2005 e suas últimas aparições, debilitado pela saúde.

Entretanto, para além da evolução imagética do astro, alguns dispositivos utilizaram para representar a morte de Michael Jackson, em suas capas, uma famosa fotografia empregada para 
a divulgação do single "Thriller", seu maior sucesso, caso dos jornais "Meia Hora", do Brasil, e "Crítica", do Panamá. Ambos empregaram a mesma fotografia, porém, a edição brasileira fez um recorte na imagem, aproximando-a.

Quanto ao texto verbal, há diferenças evidentes. 0 primeiro dispositivo, por ser de cunho mais sensacionalista, optou por um título que pode ser visto como irônico "Descanse em paz, Michael", ao mesmo tempo em que a escolha do texto da linha de apoio fica entre 0 criativo e o mau gosto. 0 texto diz "Nasceu negro, ficou branco", referindo-se às frequentes mudanças físicas do ídolo, e "vai virar cinza", remetendo à decomposição dos corpos. Além dessa escolha verbal, percebe-se, pelas demais chamadas da capa, que a publicação emprega verbos e frases na linguagem coloquial, aproximando-se da fala. Já a segunda publicação, a "Crítica", centraliza a figura de Michael Jackson na cena do videoclipe e sinaliza na manchete com "Fim do Thriller". Logo abaixo, são dispostas sete fotografias que trazem momentos marco da carreira do astro, assim como inúmeras publicações o fizeram.

Assim, é possível afirmar que Michael Jackson morreu aos 50 anos de idade, mas foi eternizado, no processo de circulação, como negro e no auge de sua carreira. Essa eleição se dá em três momentos distintos: em primeiro lugar pelo acesso às imagens da morte; segundo, pelo discurso midiático construído nos dispositivos midiáticos jornalísticos como capas de jornais e programações de TV, e, terceiro, pela apropriação e replicação desse discurso em dispositivos diversos, não só jornalísticos, mas essencialmente de atores individuais que se tornaram fundamentais para barrar 0 acesso ao espaço midiático de outras imagens que não fossem positivas à imagem do cantor.

\subsection{Entre apagamentos, eleições e replicações}

Uma imagem eleita pelas mídias só é alçada à categoria de símbolo do acontecimento, passando a constituí-lo, por meio de movimentos de circulação intermidiática, ou seja, por processos que se transformam pela produção, consumo, reinscrição em dispositivos midiáticos diversos e que resultam na alteração do espaço de circulação. Assim, a força simbólica está diretamente ligada às lógicas empregadas para fazer as imagens perdurarem no tempo, para além dos acontecimentos a que se referem.

Estas lógicas podem ser desmembradas em seis etapas: Aparecimento/Oferta - Apagamento/ Desaparecimento - Reaparecimento Replicação - Restrição - Totemização.

0 aparecimento está relacionado ao acesso, ou seja, como os fatos e suas imagens chegam às instituições jornalísticas e como são disponibilizados para serem vistos. Este deixa evidenciar as marcas das operações realizadas pelas instituições não midiáticas envolvidas, bem 
como do próprio discurso produzido/reproduzido nos dispositivos. Ou seja, trata-se de operações de produção. 0 aparecimento é, por um lado, fruto do acesso ao campo das mídias e, de outro, do trabalho feito nos dispositivos jornalísticos para sua exibição. Isto é, os fatos aparecem, bem como as imagens, mas ao ingressar no campo das mídias passam a pertencer a este espaço e, portanto, sofrem as lógicas dos meios, principalmente no que diz respeito aos mecanismos de eleição/seleção.

No que diz respeito ao apagamento, as imagens são inscritas em dispositivos diversos afetando as demais esferas do sistema comunicacional. Contudo, esses afetamentos implicam em inscrições por parte de atores individuais e de instituições não midiáticas que acabam por contribuir, via interação, para a instância do apagamento. Isto é, uma imagem replicada diversas vezes, em diversos dispositivos e que retorna ciclicamente aos dispositivos jornalísticos, tende a ser uma imagem que resiste ao apagamento, ela sofre uma espécie de "blindagem" pela circulação. No entanto, as demais imagens ofertadas permanecem existindo, mas são opacadas. Assim as imagens integram um jogo de acessibilidade x inacessibilidade, de aparecimento $\mathrm{x}$ apagamento, de visibilidade $\mathrm{x}$ desaparecimento, de acesso $\mathrm{x}$ excesso, movimentos estes que se intercalam.
Mas, para além destas binariedades, a terceira operação midiática é a de reaparecimento, quando as imagens e seus discursos recebem 0 direito de se constituírem nas únicas a serem vistas, gerando sentidos que não estão dados e que são "acrescidos" a partir do descolamento ${ }^{2} /$ deslocamento da imagem do fato inicial e da sua circulação como vetora. Isto significa dizer que o reaparecimento implica na construção ou na restrição de algo, pois há dois aspectos a serem observados aqui. 0 primeiro diz respeito ao reaparecimento da imagem vetora, o que implica numa continuidade de inscrições. 0 segundo aspecto tange ao reaparecimento de imagens que estavam opacadas, mas que em virtude de novos movimentos midiáticos precisa ser reinscrita ou recuperada. Deste modo, o reaparecimento como categoria é uma terceira etapa, a qual está diretamente articulada com a próxima.

Dentre as lógicas midiáticas empregadas para atribuir força simbólica a uma imagem está 0 potencial de replicação. A fotografia "escolhida" é disposta em diversos dispositivos jornalísticos e, ao ser reiterada em dispositivos não noticiosos, seja de atores individuais ou de instituições não midiáticas, passa a pertencer a estas instâncias de consumo produtivo, sendo que estes reforçam nos dispositivos que dominam as imagens e os discursos já postos em circulação anteriormente, ainda que produzam novos discursos e sentidos

0 termo descolamento é adotado aqui no sentido metafórico do decalque, isto é, não significa que a imagem se despreenda por completo, mas que ocorrem transformações nas relações entre as imagens significantes e a realidade referida. Então, há um descolamento e ao mesmo tempo um deslocamento. 
sobre. Desta maneira, a repetição de uma mesma imagem diversas vezes e sua inscrição em dispositivos múltiplos, jornalísticos ou não, afeta 0 acontecimento, principalmente, do ponto de vista de sua rememoração.

Entretanto não basta somente a repetição. Para além das imagens em "eco", a criação do símbolo passa, necessariamente, por uma espécie de restrição, a penúltima categoria aqui desenvolvida. A restrição é um resultado da replicação, pois quando uma imagem é inscrita demasiadamente na circulação, a referência deixa de ser 0 acontecimento e passa a ser a própria imagem midiatizada anteriormente, constituindo-se no fenômeno de autorreferencialidade. Significa, deste modo, que uma imagem é alçada à categoria de símbolo de um acontecimento quando por sua replicação, em dispositivos jornalísticos e, principalmente, de atores individuais, acaba por restringir 0 acesso de outras imagens existentes ao espaço midiático, resultando, como consequência, na restrição da interpretação e da existência de outras imagens. Em minha perspectiva, é exatamente essa imagem autorreferencial, que se torna símbolo e, nestes casos, totem ${ }^{3}$.

Em síntese, imagens são escolhidas por instituições midiáticas, são replicadas em dispositivos diversos, restringindo, num primeiro momento, o possível, ou seja, o acontecimento se refere somente àquelas imagens (autorreferencialidade), e, segundo, restringindo a interpretação e a experiência, afinal não há nada mais para ser visto. Deste modo, a restrição da interpretação está ligada ao que chamo de imagens totens, ou seja, imagens que se tornam mais do que simples metáforas visuais, mas que sobrevivem para além do tempo dos acontecimentos e se constituem em não coisas na perspectiva de Flusser, mas que não são esvaziadas de sentido, elas são, ao contrário, reificadas, investidas de uma força quase mágica.

\section{0 totem e o poder simbólico}

Verifica-se que há um consenso construído quanto às imagens simbólicas. Contudo, a replicação, por si só, não pode ser considerada o fator de criação do símbolo, isto é, a repetição mostra a formação de um consenso, mas o símbolo que é posto em circulação é uma estrutura estruturada como um produto da própria comunicação. Ou seja, o fazer das instituições midiáticas, em especial as jornalísticas, permite que sejam produzidos objetos simbólicos, meios de mediação, mas tais objetos se mantêm em circulação por um poder que é emanado de estruturas estruturantes mais profundas e que são da ordem da subjetividade.

0 que chama a atenção no que tange à midiatização das imagens é que estas são, 
num primeiro momento, aproximações

do acontecimento, considerando, aqui, representações de um dado referente. Numa segunda fase, as imagens já postas em circulação em dispositivos jornalísticos se tornam sínteses porque foram eleitas previamente, de acordo com a lógica do campo das mídias e com base em estruturas profundas do social, para adquirirem tal visibilidade. Já numa terceira etapa, a do reconhecimento, são novamente organizadas conforme regras tácitas próprias da esfera do social, o que não significa um contrato, mas envolve estruturas prévias. Isto é, o símbolo é construído em jogo, não por um ou outro jogador. Em outros termos, o símbolo que circula nos jornais, nas revistas, nos sites e blogs é fruto das interações de instituições não midiáticas, atores individuais e, principalmente, instituições midiáticas, que têm como essência o fazer jornalístico, via dispositivos midiáticos. A noção de valorização das instituições jornalísticas se deve ao fato de que são elas que organizam, previamente, as imagens a serem postas em circulação, mesmo que sejam diretamente impactadas e afetadas pelas demais esferas da midiatização como já visto anteriormente. ${ }^{4}$

Deste modo, as imagens do caso analisado, dão conta de um número amplo de fotografias e de possibilidades relacionais que se limitaram a um número cada vez menor e mais restrito de tais possibilidades e visões. As imagens vetoras foram transformadas em símbolos, em certa medida porque houve um consenso orquestrado em torno destas imagens, mas, na maioria das vezes, esta simbologia surge pelo poder de dominação que tais imagens adquirem sobre as outras, mesmo quando elas sequer são convocadas. Ainda que Michael Jackson apareça branco e de cabelos lisos, a imagem imaterial acionada coletivamente é a do astro do pop, negro, no auge de sua carreira. Como explicar esse movimento? Para Cassirer (2001) ocorre um "um novo estágio de reflexão", uma outra relação com o objeto de que trata, "atribuindo a ele e a si mesmo uma significação ideal modificada”. A essa possibilidade do acontecimento ser constituído e se constituir na imagem se chama de autorreferencialidade midiática.

No campo semiótico, percebe-se que esta autorreferência refere-se ao deslocamento de um objeto segundo, ou seja, que está no lugar de outro, que deixa de ser o referente ${ }^{5}$, rompendo com a própria categoria de símbolo e criando um elemento que passa a representar a si mesmo. Em outros termos, no momento em que a imagem ganha espaço na mídia e se configura como um

Diversos autores questionam este poder dos meios de comunicação atuais de organização do social. Harry Pross (1980) afirma que esta é a essência do jornalismo, a sincronização social. Já Moillaud acredita que esta função de organização já não estaria mais sendo cumprida pelo jornalismo em função da variabilidade de dispositivos e de visões que estes proporcionam. 0 estudo feito, aqui, indica que mesmo tendo uma ampla gama de dispositivos, as rupturas com as visões hegemônicas são bastante isoladas, muito em função do discurso de credibilidade que os meios ainda têm. 
símbolo do fato ou objeto, sobrevivendo para além do tempo do próprio acontecimento, tal imagem ingressa num outro plano, o do totêmico, isto é, passa a integrar estruturas do social que hierarquizam outras estruturas, portanto, se torna estruturante das leituras do mundo.

As imagens-totens são estas imagens autorreferenciais que são produzidas na circulação, pois elas só existem nessa tramitação, mobilizando a tríade freudiana de lembrança, repetição e perlaboração em potência. Numa primeira instância, têm-se uma lembrança do acontecimento com uma ampla gama de imagens deste inserida em dispositivos jornalísticos, depois, há um impedimento desta lembrança via repetição, portanto, restrição de acesso às possibilidades, que culmina com a perlaboração do próprio acontecimento a partir da imagem-totem que elabora novamente os sentidos produzidos sobre o próprio acontecimento. Destaca-se, porém, que uma vez que as imagens-totens são construídas através da circulação, são estruturantes de outras práticas comunicacionais, pois é a partir delas que novos discursos são elaborados.

\section{Referências}

BAITELLO JUNIOR, N. 0 animal que parou os relógios: ensaios sobre comunicação, cultura e mídia. São Paulo: Annablume, 1999.
BAITELLO JUNIOR, N. Comunicação, mídia e cultura. Perspectiva. São Paulo: Fundação Seade, outdez/1998.

BAITELLO JUNIOR, N. A era da iconofagia: ensaios de comunicação e cultura. São Paulo: Hacker Editores, 2005.

BELTING, H. Pour une anthropologie dês images. Paris: Gallimard, 2007.

BELTING, H. Likeness and presence: a history of the image before the era of art. Chicago, London: The University of Chicago Press, 1994.

BENETTI, M.; FONSECA, V. P. da S. (Org.). Jornalismo e acontecimento: mapeamentos críticos. Florianópolis: Insular, 2010.

BOURDIEU, P. 0 poder simbólico. Rio de Janeiro: Bertrand Brasil, 2011.

BOURDIEU, P. El sentido práctico. Buenos Aires: Siglo Veintieuno, 2007.

CASSIRER, E. A filosofia das formas simbólicas. São Paulo: Martins Fontes, 2004;

CASSIRER, E.A filosofia das formas simbólicas: primeira parte: a linguagem. Tradução Marion Fleischer. São Paulo: Martins Fontes, 2001.

CHARAUDEAU, P. 0 discurso da informação midiática: construção do espelho social. Paris: Nathan: 1997.

DURAND, G. Estruturas antropológicas do imaginário: introdução e arquetipologia. 2. ed. São Paulo: Martins Fontes, 2001.

DURKHEIM, É. As formas elementares da vida religiosa: 0 sistema totêmico na Austrália. 4.ed. São Paulo: Martins Fontes, 2009. 
FERREIRA, J.; ROSA, A. Midiatização e poder. In:

TEMER, A. Mídia, cidadania e poder. Goiânia: FACOMB:

FUNAPE, 2011.

FERREIRA, J. Epistemologia e novo habitus (o caso como conhecimento social e individual). Ícone, Recife, v. 11, p. 1-12, 2009 .

FERREIRA, J. Midiatização: dispositivos, processos sociais e de comunicação. Paper: PPGCOM São Leopoldo, 2008.

FLUSSER, V. 0 mundo codificado: por uma filosofia do design e da comunicação. Organizado por Rafael Cardoso. São Paulo: Cosac Naify, 2007.

FLUSSER, V. Filosofia da caixa preta: ensaios para uma futura filosofia da fotografia. Rio de Janeiro: Relume Dumará, 2002.

GOMES, P. G. Os processos midiáticos como objeto de estudo. In: GOMES, P. G. Tópicos da teoria da Comunicação. São Leopoldo: Unisinos, 2004.

KAMPER, D. Os padecimentos dos olhos. In: CASTRO, G.; CARVALHO, E.; ALMEIDA, M. C. (Org.). Ensaios de Complexidade. Porto Alegre: Sulina, 1997. p. 131-137.

KAMPER, D. Imagem. In: BODEI, R.; BORSARI, A.; WULF, C. Cosmo, corpo, cultura: enciclopédia antropológica. A cura de Christoph Wulf. Milano, Itália: B. Mondadori, 2002.

NEWSEUM. Disponível em: < http://www. newseum.org/todaysfrontpages/default_archive. asp?fpArchive $=062609>$. Acesso em: 13/02/2014

NUNES, M. R. F. A memória na mídia: a evolução dos memes de afeto. São Paulo: Annablume, 2001.

QUÉRÉ, L. Entre o facto e o sentido: a dualidade do acontecimento. Trajectos, Lisboa, n. 6, p. 59-75, 2005.

SODRÉ, M. Estratégias sensíveis: afeto, mídia e política. Petropólis, RJ: Vozes, 2006. 
Totem images and circulation: journalistic approval in Michael Jackson's case

Imagenes Toténs y circulación: la chancel periodística sobre el caso Michael Jackson

\section{Abstract}

This article intends to investigate the strategies that are promoted to put journalistic images in circulation. So this is a study about what is distributed by media and is reinstated in several devices, therefore, at the same time circulation and circularity. Thus starting with the presupposition that more and more there is an increasing number of images being offered, there is, however, a small number of images which fix themselves, so called vector images, or which become totem exactly because of their potential for fixation and self-referential communication, since they convene deep structures of the imaginary and are journalistically approved.

\section{Keywords}

Photojournalism. Media. Symbolism. Circulation.

\section{Resumen}

Este artículo tiene como objetivo investigar las estrategias que se promueven al poner en circulación imágenes periodísticas. Entonces se trata de un estudio de lo que se distribuye midiaticamente y ló que es reinscrito en muchos dispositivos, ló que mientras circulación y circularidad. Por lo tanto, se parte de la suposición de que, cada vez mas hay un número creciente de imágenes ofrecido, sin embargo, hay un pequeño número de imágenes que se fijan, llamadas los vectores, ou que se ló convierten en tótems por su potencial de la fijación y la auto-referencialidad, pero convocan a las estructuras profundas de lo imaginario y son chanceladas periodísticamente.

\section{Palabras-Clave}

Fotoperiodismo. Midiatización. Símbolos. Circulación. 


\section{Expediente}

A revista E-Compós é a publicação científica em formato eletrônico da Associação Nacional dos Programas de Pós-Graduação em Comunicação (Compós). Lançada em 2004, tem como principal finalidade difundir a produção acadêmica de pesquisadores da área de Comunicação, inseridos em instituições do Brasil e do exterior.

\section{E-COMPÓS I www.e-compos.org.br I E-ISSN 1808-2599}

Revista da Associação Nacional dos Programas

de Pós-Graduação em Comunicacão.

Brasília, v.17, n.2, mai./ago. 2014.

A identificação das edições, a partir de 2008

passa a ser volume anual com três números.

\section{CONSELHO EDITORIAL}

Afonso Albuquerque, Universidade Federal Fluminense, Brasil Alberto Carlos Augusto Klein, Universidade Estadual de Londrina, Brasil Alex Fernando Teixeira Primo, Universidade Federal do Rio Grande do Sul, Brasil Rio Grande do Sul, Brasi

Ana Gruszynski, Universidade Federal do Rio Grande do Sul, Brasil Ana Silvia Lopes Davi Médola, Universidade Estadual Paulista, Brasil André Luiz Martins Lemos, Universidade Federal da Bahia, Brasi Ângela Freire Prysthon, Universidade Federal de Pernambuco, Brasil Antônio Fausto Neto, Universidade do Vale do Rio dos Sinos, Brasil Antonio Carlos Hohlfeldt, Pontifícia Universidade Católica do Rio Grande do Sul, Brasil Antonio Roberto Chiachiri Filho, Faculdade Cásper Líbero, Brasi Arlindo Ribeiro Machado, Universidade de São Paulo, Brasil Arthur Autran Franco de Sá Neto, Universidade Federal de São Carlos, Brasil Benjamim Picado, Universidade Federal Fluminense, Brasil César Geraldo Guimarães, Universidade Federal de Minas Gerais, Brasil Cristiane Freitas Gutfreind, Pontifícia Universidade Católica do Rio Grande do Sul, Brasil Denilson Lopes, Universidade Federal do Rio de Janeiro, Brasil Denize Correa Araujo, Universidade Tuiuti do Paraná, Brasi Edilson Cazeloto, Universidade Paulista , Brasil

Eduardo Vicente, Universidade de São Paulo, Brasil Eneus Trindade, Universidade de São Paulo, Brasil Erick Felinto de Oliveira, Universidade do Estado do Rio de Janeiro, Brasi Florence Dravet, Universidade Católica de Brasília, Brasil Gelson Santana, Universidade Anhembi/Morumbi, Brasi Gilson Vieira Monteiro, Universidade Federal do Amazonas, Brasil Gislene da Silva, Universidade Federal de Santa Catarina, Brasil Guillermo Orozco Gómez, Universidad de Guadalajara Gustavo Daudt Fischer, Universidade do Vale do Rio dos Sinos, Brasil Hector Ospina, Universidad de Manizales, Colômbia Herom Vargas, Universidade Municipal de São Caetano do Sul, Brasil Ieda Tucherman, Universidade Federal do Rio de Janeiro, Brasil Inês Vitorino, Universidade Federal do Ceará, Brasil Janice Caiafa, Universidade Federal do Rio de Janeiro, Brasil Jay David Bolter, Georgia Institute of Technology Jeder Silveira Janotti Junior, Universidade Federal de Pernambuco, Brasi João Freire Filho, Universidade Federal do Rio de Janeiro, Brasil John DH Downing, University of Texas at Austin, Estados Unidos Ana Carolina Damboriarena Escosteguy, Pontifícia Universidade Católica do

José Afonso da Silva Junior, Universidade Federal de Pernambuco, Brasil José Carlos Rodrigues, Pontifícia Universidade Católica do Rio de Janeiro, Brasil José Luiz Aidar Prado, Pontifícia Universidade Católica de São Paulo, Brasil José Luiz Warren Jardim Gomes Braga, Universidade do Vale do Rio dos Sinos, Brasil Juremir Machado da Silva, Pontifícia Universidade Católica do Rio Grande do Sul, Brasil Laan Mendes Barros, Universidade Metodista de São Paulo, Brasil Lance Strate, Fordham University, USA, Estados Unidos Lorraine Leu, University of Bristol, Grã-Bretanha Lucia Leão, Pontifícia Universidade Católica de São Paulo, Brasil Luciana Panke, Universidade Federal do Paraná, Brasil Luiz Claudio Martino, Universidade de Brasília, Brasil Malena Segura Contrera, Universidade Paulista, Brasil Márcio de Vasconcellos Serelle, Pontifícia Universidade Católica de Minas Gerais, Brasil Maria Aparecida Baccega, Universidade de São Paulo e Escola Superior de Propaganda e Marketing, Brasil Maria das Graças Pinto Coelho, Universidade Federal do Rio Grande do Norte, Brasil Maria Immacolata Vassallo de Lopes, Universidade de São Paulo, Brasil Maria Luiza Martins de Mendonça, Universidade Federal de Goiás, Brasil Mauro de Souza Ventura, Universidade Estadual Paulista, Brasil Mauro Pereira Porto, Tulane University, Estados Unidos Nilda Aparecida Jacks, Universidade Federal do Rio Grande do Sul, Brasil Paulo Roberto Gibaldi Vaz, Universidade Federal do Rio de Janeiro, Brasil Potiguara Mendes Silveira Jr, Universidade Federal de Juiz de Fora, Brasil Renato Cordeiro Gomes, Pontifícia Universidade Católica do Rio de Janeiro, Brasil Robert K Logan, University of Toronto, Canadá

Ronaldo George Helal, Universidade do Estado do Rio de Janeiro, Brasil Rosana de Lima Soares, Universidade de São Paulo, Brasi Rose Melo Rocha, Escola Superior de Propaganda e Marketing, Brasil Rossana Reguillo, Instituto de Estudos Superiores do Ocidente, Mexico Rousiley Celi Moreira Maia, Universidade Federal de Minas Gerais, Brasi Sebastião Carlos de Morais Squirra, Universidade Metodista de São Paulo, Brasil Sebastião Guilherme Albano da Costa, Universidade Federal do Rio Grande do Norte, Brasil

Simone Maria Andrade Pereira de Sá, Universidade Federal Fluminense, Brasi Tiago Quiroga Fausto Neto, Universidade de Brasília, Brasil Suzete Venturelli, Universidade de Brasília, Brasil Valerio Fuenzalida Fernández, Puc-Chile, Chile Veneza Mayora Ronsini, Universidade Federal de Santa Maria, Brasil Vera Regina Veiga França, Universidade Federal de Minas Gerais, Brasil

\section{COMISSÃO EDITORIAL}

Cristiane Freitas Gutfreind I Pontifícia Universidade Católica do Rio Grande do Sul, Brasil Irene Machado I Universidade de São Paulo, Brasil

Jorge Cardoso Filho I Universidade Federal do Reconcavo da Bahia, Brasil / Universidade Federal da Bahia, Brasil

CONSULTORES AD HOC

Adriana Amaral, Universidade do Vale do Rio dos Sinos, Brasil

Alexandre Rocha da Silva, Universidade Federal do Rio Grande do Sul, Brasi Arthur Ituassu, Pontifícia Universidade Católica do Rio de Janeiro, Brasil Bruno Souza Leal, Universidade Federal de Minas Gerais, Brasil Elizabeth Bastos Duarte, Universidade Federal de Santa Maria, Brasil Francisco Paulo Jamil Marques, Universidade Federal do Ceará, Brasi Maurício Lissovsky, Universidade Federal do Rio de Janeiro, Brasil Suzana Kilpp, Universidade do Vale do Rio dos Sinos, Brasil Vander Casaqui, Escola Superior de Propaganda e Marketing, Brasil

EDIÇÃO DE TEXTO E RESUMOS I Susane Barros SECRETÁRIA EXECUTIVA I Helena Stigger EDITORAÇÃo ELETRÔNICA I Roka Estúdio
COMPÓS I www.compos.org.br

Associação Nacional dos Programas de Pós-Graduação em Comunicação

Presidente

Eduardo Morettin

Universidade de São Paulo, Brasil

eduardomorettin@usp.br

Vice-presidente

Inês Vitorino

Universidade Federal do Ceará, Brasil

ines@ufc.br

Secretária-Geral

Gislene da Silva

Universidade Federal de Santa Catarina, Brasil

gislenedasilva@gmail.com 